\title{
Food fortification
}

\author{
BY D. P. RICHARDSON \\ The Nestlé Company Lid, St George's House, Croydon, Surrey CR9 INR
}

Many nutrition surveys in developed and developing countries continue to indicate that an appreciable fraction of the population, particularly young children, adolescents, the elderly and women of child-bearing age can suffer from nutrient deficiencies at a borderline or pathological level. In the developed nations, nutrient needs and food choices of these specific population groups, the increasing use of dietetic and low-energy products, the overall trend towards consuming fewer calories and the greater reliance on commercially prepared foods are just some of the reasons why it is essential to re-examine policies and guidelines for the addition of nutrients to foods.

Advances in food technology and new manufacturing processes have also created the possibilities for increased and decreased exposure to some essential nutrients (Harris \& Karmas, 1977; Bender, 1978; British Nutrition Foundation. 1987). Generally, the advantages of food processing and food preparation are to arrest spoilage, to make foods safe and edible and, hence, to minimize the deterioration in the nutritional quality of the food. Although the concerns about losses of specific nutrients in various processes have to be considered in the context of the diet as a whole, the addition of micronutrients has been used to maintain or enhance the nutritional value of many commonly consumed foods. Developments of 'novel' foods such as margarine, low-fat spreads and vegetable protein meat analogues which simulate existing foods have also raised questions of 'nutritional equivalency' in terms of the amount and bioavailability of added nutrients (Ministry of Agriculture, Fisheries and Food, 1974).

The addition of nutrients is accomplished using the techniques of fortification or enrichment, restoration, standardization and supplementation. Fortification or enrichment refers specifically to the addition of nutrients to a food above the level normally found in that food; restoration refers to replacement of nutrients whose losses cannot be avoided during handling, processing and storage of foods; standardization refers to the addition of nutrients to a food to compensate for natural variations; and supplementation, a more general term, refers to the addition to a food of nutrients which are not normally contained in that food or only in minute quantities.

\section{GENERAL POLICIES FOR NUTRIENT ADDITIONS}

Several nutrients have been added to food and drink products around the world, as public health measures and as cost-effective ways of ensuring the nutritional quality of the food supply. Addition of some nutrients has also formed the basis of marketing strategies in product development. In general, the main criteria for selecting nutrients to be added to foods are that they are shown to be necessary, safe and effective (National Academy of Sciences, 1975). The addition of nutrients also requires careful attention to food regulations, labelling, nutritional rationale, cost, the acceptability of the product to consumers and a careful assessment of technical and analytical limitations for compliance with label declarations. 
Nutrient enrichment of foods can help prevent nutritional inadequacies in populations where there is a risk of deficiencies and where intervention is needed to correct a proven deficiency in an identified segment of the population. In this case, the criteria of effectiveness are whether or not nutrition status and health have been improved. When nutrient additions are part of a marketing and promotional strategy, a fundamental question is whether their presence will sell more products. The effectiveness of a programme of nutrient additions is influenced by whether the food that is to carry the nutrient(s) is going to be acceptable, consumed by those who need or want it and be at a price they can afford. Also, the nutrients must be bioavailable and sufficiently stable under the normal, and perhaps unusual, conditions of storage and household use. Evidence and assurances must also be sought to ensure that consumption of foods containing added nutrients will not create a nutritional imbalance and that an excessive intake of the nutrients will not occur, bearing in mind the cumulative amounts from other sources in the diet. General principles for the addition of nutrients to foods have been established by the Codex Alimentarius Commission (1987) of the Food and Agriculture Organization/World Health Organization, and the United States Food and Drug Administration (1987b).

\section{LEGISLATION CONCERNING THE ADDITION OF NUTRIENTS TO FOODS}

The regulations concerning the addition of nutrients to foods and the authority to make claims vary from one country to another, and many problems can arise for food manufacturers owing to the lack of harmonization in this field (du Bois, 1987). Differences in methods of analysis and the variations in the lists of recommended daily amounts (RDA) of the nutrients are also problems which are encountered by food manufacturers selling the same products on an international basis. In addition, the reference points for addition of nutrients can be per $100 \mathrm{~g}$, per $\mathrm{kg}$, per $100 \mathrm{kcal}$, per food serving (in grams) or the amounts of a food which can be reasonably consumed daily (in grams). The serving sizes of daily portions can, of course, vary considerably from one population to another depending on their eating habits.

Four categories of foodstuffs can be identified where the addition of vitamins and minerals is compulsory in some countries: (a) foods for special dietary uses, (b) foods having lost nutrients during manufacture, (c) foods resembling a common food (replacement products) and (d) staple foods representing ideal vehicles for nutrients.

\section{Food for special dietary uses}

As defined by the Council of the European Communities, foods for special dietary uses or foods for particular nutritional uses are foodstuffs which, owing to their special composition or manufacturing process, are clearly distinguishable from foodstuffs for normal consumption, which are suitable for their claimed nutritional purposes and which are marketed in such a way as to indicate such suitability (European Council Directive, 1987). A particular nutritional use must fulfil the particular nutritional requirements: (a) of certain categories of persons whose digestive processes or metabolism are disturbed; or (b) of certain categories of persons who are in a special physiological condition and who are, therefore, able to obtain a special benefit from a controlled consumption of certain substances in foodstuffs; or (c) of infants or young children in good health. 
An excellent example is the development of nutritional standards for the composition of infant formulas which are complete foods intended for use, where necessary, as a substitute for human milk and should meet the normal nutritional requirements of infants up to 4-6 months of age. Nutrient standards for nutritionally complete formula foods for use in weight-control diets and standards for 'low energy' and 'reduced energy' foods are also under consideration in the European Economic Community, and the Codex Alimentarius Commission (1985), but the issues go beyond the scope of the present paper.

\section{Foods having lost nutrients during manufacture}

The best example of the compulsory restoration of the level of vitamins and minerals lost during manufacture in the UK is the addition of nutrients to all types of flour, other than wholemeal flour. The quality of flours is regulated by the Bread and Flour Regulations (1984) and low-extraction flours have to be enriched by the addition of thiamin $(0.24$ $\mathrm{mg}$ ), niacin ( $1.60 \mathrm{mg}$ ), iron ( $1.65 \mathrm{mg}$ ) and calcium (235 mg minimum-390 mg maximum)/ $100 \mathrm{~g}$. The Department of Health and Social Security (DHSS) (1981) reviewed the nutritional aspects of bread and flour and recommended that these additions be no longer mandatory. However, taking into consideration, for example, the fact that flour-based products provide about one-fifth of the thiamin intake in the diet of the elderly (D. J. Thurnham, personal communication) it is not surprising that the DHSS (1981) recommendation was not accepted in drawing up the new law.

In Denmark, flour must contain vitamin $\mathrm{B}_{1}$ (thiamin) ( $5 \mathrm{mg}$ ), vitamin $\mathrm{B}_{2}$ (riboflavin) (5 $\mathrm{mg}), \mathrm{Ca}(2 \mathrm{~g})$ and $\mathrm{Fe}(30 \mathrm{mg}) / \mathrm{kg}$ and rolled oats must contain $\mathrm{Ca}(2 \cdot 3 \mathrm{~g} / \mathrm{kg})$ and phosphorus $(1.8 \mathrm{~g} / \mathrm{kg})$. Similarly, in the USA, most low-extraction rate flours are enriched with thiamin, riboflavin, nicotinamide and Fe up to $0.44,0.26,3.5$ and 2.9 mg/100 g respectively (Bender, 1978; du Bois, 1987).

The additions of vitamins $A$ and $D$ to skim-milk powder and the addition of vitamin $D$ to evaporated milk in the UK are also, in part, examples of voluntary forms of vitamin restoration.

\section{Foods resembling a common food}

The best example is the addition of vitamins $\mathrm{A}$ and $\mathrm{D}$ to margarine, which was first made statutory in the UK at the start of World War II. By law, margarine must contain $804 \mu \mathrm{g}$ retinol and $8 \mu \mathrm{g}$ vitamin $\mathrm{D} / 100 \mathrm{~g}$ to give it a nutritive value similar to that of butter. This compulsory addition of nutrients (Margarine Regulations, 1967) was a major public health measure and formed an important part of the efforts to prevent rickets. The addition of vitamins $A$ and $D$ is also compulsory in Belgium, Denmark, The Netherlands, Norway and Sweden.

In the UK, the Committee on Medical Aspects of Food Policy (COMA) (DHSS, 1980) laid down the general principle that 'any substance promoted as a replacement or an alternative to a natural food should be nutritionally equivalent in all but unimportant aspects of the natural food which it would simulate'. Thus the Food Standards Committee (FSC) (Ministry of Agriculture, Fisheries and Food, 1974) and the COMA panel (DHSS, 1980) gave their recommendations and specifications for the nutritional quality and use of textured vegetable protein (TVP) foods which simulate meat. In the UK, the FSC recommended that TVP shall contain (/100 g dry matter) not less than $2 \cdot 0$ 
$\mathrm{mg}$ thiamin, $0.8 \mathrm{mg}$ riboflavin, $5.0 \mu \mathrm{g}$ vitamin $\mathrm{B}_{12}$ and $10 \mathrm{mg} \mathrm{Fe}$. The nutritional aspects and acceptability of vegetable protein foods which simulate meat have been described in detail elsewhere (Richardson, 1982).

\section{Staple foods}

Vitamin A deficiency and xerophthalmia are among the most widespread nutritional disorders that result in blindness in man, particularly in tropical and subtropical countries. One of the remedies is the fortification of staple foods. In India, for example, since tea is consumed universally (even by small children), this drink is used as the vehicle for enrichment. Other staples used for enrichment with vitamin A include rice and table sugar in Guatemala and monosodium glutamate in the Philippines (Bender, 1978). As previously stated, vitamins $A$ and D are customarily added to skim-milk powders and evaporated milk.

Well-established examples of the benefits of trace element additions include elimination of goitre through iodization of salt, the decrease in dental caries through fluoridation of the water supply and the addition of Fe to bread and cereals, table salt, monosodium glutamate, sugar, coffee, tea, oils and fats.

\section{CLAIMS FOR NUTRIENTS AND THE LABELLING OF FORTIFIED FOODS}

In the UK, the addition of vitamins and minerals is permitted to all foodstuffs with the exception of alcoholic drinks. Claims may be made only with respect to the 'scheduled' nutrients as stated in the Food Labelling Regulations (1984). These nutrients are the vitamins: $\mathrm{A}$, thiamin, riboflavin, niacin, folic acid, $\mathrm{B}_{12}, \mathrm{C}$ and $\mathrm{D}$, and the minerals: $\mathrm{Ca}$, iodine and $\mathrm{Fe}$. If a claim is made on the label that a food is a 'rich' or 'excellent' source of vitamins or minerals, then the daily food portion (described as 'the quantity of food that can reasonably be expected to be consumed in a day') must contain at least half the RDA for that nutrient. For any other claim, e.g. 'a useful source' or 'with added . . ', the daily portion must contain at least one-sixth of the RDA. Table 1 summarizes the labelling requirements for vitamin and mineral claims and lists the RDA for the scheduled nutrients.

In Switzerland and Germany, a reference on the label to a given vitamin may only be made if at least one-third of the RDA is contained in the daily food portion, and a specific claim, e.g. 'rich in', is permitted only if $100 \%$ of the RDA is contained in the daily portion. Priority in these countries is given to restoration, and the maximum addition of vitamins should not exceed three times the defined RDA (du Bois, 1987).

In the USA, when nutrition claims are made on the label or in advertising, and when nutrients are added to foods, full nutrition labelling becomes mandatory (Richardson, 1981). Nutrition information must be presented in a standard format. Briefly, the upper portion of the nutrition label shows the amount of energy ( $\mathrm{kJ}$ or kcal) in a quantified serving of the food, and lists in $g$ the amount of protein, carbohydrate, fat and sodium. The lower portion of the label shows the percentage of the (US) RDA for protein, five vitamins (vitamins $\mathrm{A}, \mathrm{C}$, thiamin, riboflavin and niacin) and minerals ( $\mathrm{Ca}$ and $\mathrm{Fe}$ ) provided in one serving. A manufacturer may elect to list further vitamins and minerals for which (US) RDA have been established (United States Food and Drug Administration (1987a)) nutrition labelling regulations. 
Table 1. The types and conditions for vitamin and mineral claims on food labels and the recommended daily amounts of nutrients as specified by the Food Labelling Regulations (1984). Conditions for mineral and vitamin claims are the same

(a) Nutrients in respect of which claims may be made

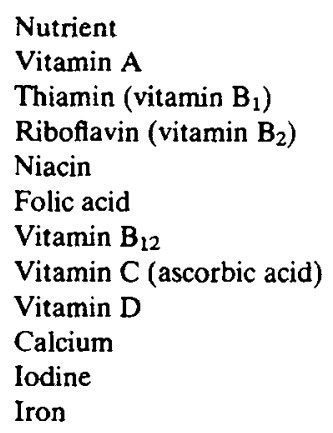

Recommended daily amount (RDA)
$750 \mu \mathrm{g}$
$1.2 \mathrm{mg}$
$1.6 \mathrm{mg}$
$18 \mathrm{mg}$
$300 \mu \mathrm{g}$
$2 \mu \mathrm{g}$
$30 \mathrm{mg}$
$2.5 \mu \mathrm{g}$
$500 \mathrm{mg}$
$140 \mu \mathrm{g}$
$12 \mathrm{mg}$

(b) Claims confined to named vitamins
Rich or excellent source,
e.g. 'rich in vitamin $\mathrm{C}$ ' 1/2 RDA
Any other case, e.g. 'useful source of vitamin C' 1/6 RDA

In a quantity of food that can be reasonably consumed in a day

+\% RDA in a quantified serving and no. of such servings in package

(c) Claims NOT confined to named vitamins

\begin{abstract}
Rich or excellent source,
e.g. 'an excellent source of vitamins' 1/2 RDA
\end{abstract}

Of TWO or more scheduled vitamins

In a quantity of food that can be reasonably consumed in a day

$+\%$ RDA in a quantified serving of the vitamins enabling the claim to be made and no. of servings in the package

\section{RESTRICTIVE REGULATIONS AND POLICIES ON HEALTH CLAIMS}

As a general policy, the indiscriminate additions of nutrients to foods should be discouraged and information on food labels should not over-emphasize or distort the role of a single food or component in enhancing good health. In the UK, implicit claims for the presence of vitamins and minerals are already controlled by the Food Labelling Regulations (1984). Claims as to the suitability of a food for use in the prevention, alleviation, treatment or cure of a disease, disorder or particular physiological condition are prohibited unless they follow strict rules for such foods, as those for Special Dietary Uses. More recently, however, there has been a trend towards more explicit healthrelated and disease-prevention claims, e.g. $\mathrm{Ca}$ and osteoporosis, vitamin $\mathrm{C}$ and the cure and prevention of colds, B vitamins to release stress and tension, etc.

More recently, amid a storm of controversy, a report was published on the effect of vitamin and mineral supplementation on non-verbal intelligence of a group of Welsh 
schoolchildren (Benton \& Roberts, 1988). Although, in the past, studies have linked dietary inadequacy with adverse psychological effects, the implication of these results is that the study must be repeated under more controlled conditions to confirm the findings and to understand any underlying mechanisms. Clearly, any long-term improvement to the nutritional status of the children should be through a change in diet rather than via nutrient supplementation (Taitz, 1988). Nevertheless, individuals and mothers with children are concerned to ensure adequate intakes of nutrients to promote good health, and this would account for the current market interest in the benefits of vitamin and mineral supplements.

While health and benefit claims and statements on labels and promotions can be an important way of conveying nutrition information to the public, there is concern that without sufficient control or guidance, such claims could furnish misleading information (Freckleton et al. 1989). The basic problems are how to allow valid, appropriate health claims and statements without opening the door to misleading and fraudulent clains, and to ensure that disease prevention and health benefits are founded on, and are consistent with, widely accepted, well-substantiated, peer-reviewed scientific publications.

Further complexities in implementing health claims and statements on food labels are related to the amount and kind of scientific information necessary to substantiate them, the handling of conflicting claims (e.g. for a food containing components, some of which are perceived to be beneficial and others which are perceived to be harmful).

There is some concern about the difficulty in simplifying complex health messages to fit the limited space on labels, and the potential threat of nutritional 'power races' among food companies to gain a competitive edge. To maximize their effectiveness, healthier eating and nutrition claims and statements on labels need to be used in conjunction with other methods of nutrition education.

In France, to avoid possible indiscriminate fortification and possible imbalance of nutrients, there is a general reluctance to allow the widespread addition of nutrients to foods. According to French legislation, enrichment, standardization and supplementation with vitamins are permitted only for foods for special dietary uses, e.g. infant foods or low-energy foods. Nothing is added to margarine, and there are only two situations when normal foods for healthy adults may bear the label claim "with a guaranteed vitamin content': (a) in the case of special processing which maintains the natural amount of vitamins unaltered, and (b) in the case of restoration with vitamins to compensate losses during manufacture (the aim of restoration is $80-200 \%$ of the naturally occurring vitamin content in the raw materials).

Similarly, in the framework of a general anti-additive policy, The Netherlands, Norway and Finland have a very restrictive legislation where no optional addition of vitamins and minerals to food is permitted. The regulations governing the additions of nutrients in different countries have been addressed by Bender (1978) and du Bois (1987).

THE STABILITY OF VITAMINS

During the manufacture, storage and preparation of foodstuffs, vitamins are exposed to a wide range of physical and chemical factors as shown in Fig. 1 (Killeit, 1988). The stability of these nutrients is important to the manufacturer on at least four counts: (a) the technologist needs to know the extent to which the food processes and the 


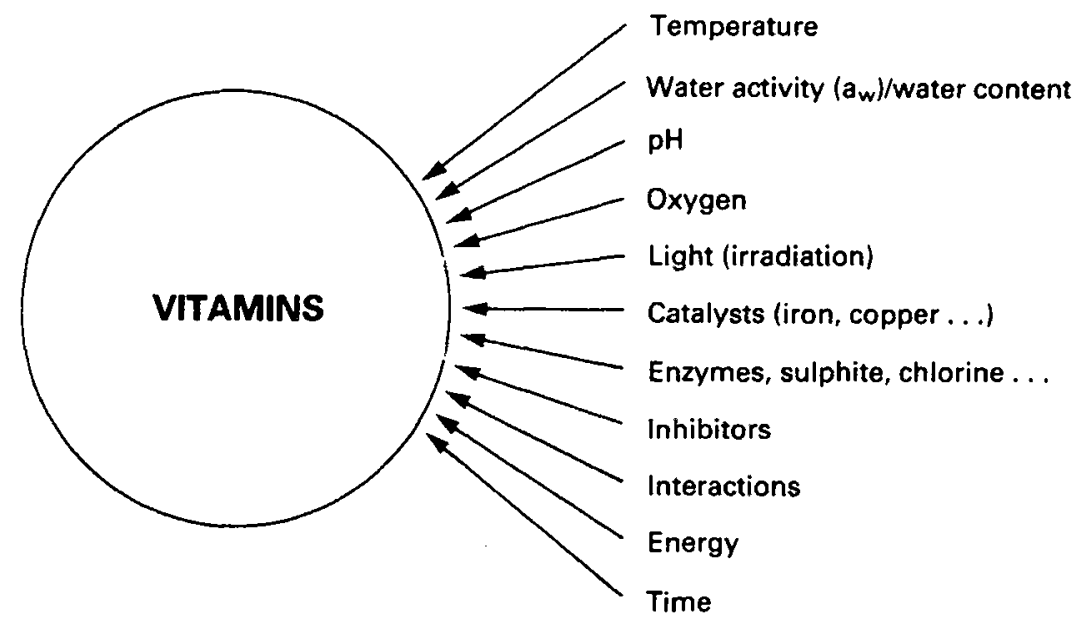

Fig. 1. Factors influencing the stability of vitamins and their retention in foods (Killeit, 1988).

distribution systems could affect the retention of the micronutrients, and try to minimize losses; (b) the quality and legislative specialist requires to have detailed information, particularly if claims for vitamin content are being made on the label; (c) the accountant will need to establish and justify expenditures on the potential for modification of processing techniques, the costs of nutrient premixes and the 'overages' of less-stable vitamins; (d) the nutritionist will have to assess the choice and ultimately the supply of the nutrient(s) to the consumer.

Obviously, with the varied nature of each vitamin, the possibility of each combination of added vitamins interacting in different ways with the food matrix, and the infinite number of ways of preparation, cooking and storage of foods, it is virtually impossible to generalize on the effects of individual factors on stability. Nevertheless, a huge amount of information has been collected on the behaviour of individual vitamins and, in the majority of cases it is possible to make good predictions as to the losses to be expected for new and modified products and processes. Table 2 summarizes the sensitivity of vitamins to external factors (Killeit, 1988; Vitamin Information Service, 1988).

The addition of nutrients to a food product is usually achieved by the use of well-defined premixes, nutricubes or pre-enriched ingredients. Some vitamins are also available in stabilized or encapsulated forms to improve retention in food processing. Guidelines for the forms of micronutrients, methods of adding, and engineering factors have been summarized by Bauernfeind \& Brooke (1973). The vitamin fortification of foods has recently been reviewed by Counsell (1988).

\section{ADDITIONS OF IRON SOURCES TO FOODS AND DRINKS}

One of the earliest recorded examples of fortification and therapeutic application of trace elements was in $4000 \mathrm{BC}$, when the Persian physician Melampus, medical adviser to Jason and the Argonauts, prescribed a diet including sweet wine laced with Fe filings to strengthen the sailors' resistance to spears and arrows and enhance their sexual potency 
Table 2. The sensitivity of vitamins to external factors (Killeit, 1988)

\begin{tabular}{lcccccc}
\hline & & & & \multicolumn{3}{c}{$\mathrm{pH}$} \\
\cline { 5 - 7 } Vitamin & Heat & Oxygen & Light & $<7$ & 7 & $>7$ \\
\hline A & - & - & - & - & + & + \\
D & - & - & - & + & + & - \\
E & $-(+)$ & $-(+)$ & $-(+)$ & $+(+)$ & $+(+)$ & $+(+)$ \\
K & + & + & - & - & + & - \\
C & - & - & - & + & - & - \\
Thiamin & - & - & + & + & - & - \\
Riboflavin & + & + & - & + & + & - \\
B6 & + & + & + & + & + & + \\
B & + & - & - & + & + & + \\
Biotin & + & + & + & + & + & + \\
Folic acid & + & + & - & - & - & + \\
Niacin & + & + & + & + & + & + \\
Pantothenic acid & - & + & + & - & + & - \\
\hline \hline
\end{tabular}

+ , Stable; -, unstable; $(+)$, esterified as tocopheryl acetate.

(Frazer, 1935). Efficacy of this particular tonic was never proven, but the story goes on to describe how, while in search of the golden fleece, Jason and his crew had many adventures and how they lingered too long with the women of Lemnos. As has been reported subsequently, the nutritional rationale for this prescription was amazingly far-sighted and even today, none of the other trace elements attract more attention than $\mathrm{Fe}$.

Benefits derived from added Fe depend on the form of salts employed, uniformity of the food fortified, and composition of the meal and total diet in which the food article is eaten (Federation of American Societies for Experimental Biology, 1980). In general, Fe compounds which exhibit the best bioavailability tend to cause adverse technological and nutritional effects in products. These effects may hinder consumer acceptability. Fe sources currently used in food fortification are shown in Table 3. The major chemical characteristics of Fe sources which determine their behaviour in foods are: (a) their solubility, ferrous salts are more soluble than ferric salts; (b) their oxidative state, ferrous salts are more efficiently utilized than ferric salts (in man) and tend to be more reactive in food systems; (c) their ability to form complexes which are not bioavailable, generally, ferric-Fe has a greater tendency to form chelates than ferrous-Fe.

The ferric form $\left(\mathrm{Fe}^{3+}\right)$ and its reduced form $\left(\mathrm{Fe}^{2+}\right)$ are the only states which occur naturally in foods. Elemental $\mathrm{Fe}$ is found rarely in biological systems, but is used widely as an added nutrient. The presence of metal ions such as Fe can: (a) speed up vitamin degradation and loss of nutritional value of a product, particularly for vitamin $C$, thiamin and retinol, (b) catalyse the oxidative rancidity of oils and fats, (c) produce undesirable colours, colour fading, off-flavours and undesirable precipitates.

Many of these effects occur as a result of interactions between natural food components such as anthocyanins, flavanoids and tannins with metal ions. For example, all bioavailable $\mathrm{Fe}$ compounds discolour dehydrated mashed potato; a black colour results when ferrous salts react with tannins present in cocoa products; and 'beer haze' is 
Table 3. Selected iron sources currently used in food fortification, together with their common names, formulas, Fe contents and relative biological values (Richardson, 1983)

\begin{tabular}{|c|c|c|c|c|}
\hline Compound & $\begin{array}{l}\text { Other } \\
\text { common names }\end{array}$ & Formula & $\begin{array}{c}\mathrm{Fe} \\
\text { content } \\
(\mathrm{g} / \mathrm{kg})\end{array}$ & $\begin{array}{c}\text { Relative } \\
\text { biological } \\
\text { value* } \\
\text { (RBV) }\end{array}$ \\
\hline Ferric phosphate & Ferric orthophosphate & $\mathrm{FePO}_{4 .} \mathrm{XH}_{2} \mathrm{O} \dagger$ & 280 & $3-46$ \\
\hline Ferric pyrophosphate & Iron pyrophosphate & $\mathrm{Fe}_{4}\left(\mathrm{P}_{2} \mathrm{O}_{7}\right)_{3} .9 \mathrm{H}_{2} \mathrm{O}$ & 250 & 45 \\
\hline $\begin{array}{l}\text { Ferric sodium } \\
\text { pyrophosphate }\end{array}$ & $\begin{array}{l}\text { Sodium Fe } \\
\text { pyrophosphate }\end{array}$ & $\mathrm{FeNaP} \mathrm{O}_{3} .2 \mathrm{H}_{2} \mathrm{O}$ & 150 & 14 \\
\hline Ferric ammonium citrate & & $\mathrm{Fe}_{x} \mathrm{NH}_{3}\left(\mathrm{C}_{6} \mathrm{H}_{8} \mathrm{O}_{7}\right)_{x}$ & 170 & 107 \\
\hline Ferrous fumarate & & $\mathrm{Fe}\left(\mathrm{C}_{4} \mathrm{H}_{2} \mathrm{O}_{4}\right)$ & 330 & 95 \\
\hline Ferrous gluconate & & $\mathrm{Fe}\left(\mathrm{C}_{6} \mathrm{H}_{12} \mathrm{O}_{7}\right) x$ & 120 & 97 \\
\hline Ferrous lactate & & $\mathrm{Fe}\left(\mathrm{C}_{3} \mathrm{H}_{5} \mathrm{O}_{3}\right)_{2} 3 \mathrm{H}_{2} \mathrm{O}$ & 380 & - \\
\hline Ferrous sulphate & & $\mathrm{FeSO}_{4} .7 \mathrm{H}_{2} \mathrm{O}$ & 320 & $100 \ddagger$ \\
\hline $\mathrm{Fe}$ & $\begin{array}{l}\text { Elemental } \mathrm{Fe} \\
\text { ferrum reductum, } \\
\text { metallic } \mathrm{Fe}\end{array}$ & $\mathrm{Fe}$ & 1000 & - \\
\hline $\begin{array}{l}\text { Reduced } \mathrm{Fe}, \mathrm{H}_{2} \text { or } \mathrm{CO} \\
\text { process }\end{array}$ & & $\mathbf{F e}$ & 960 & 34 \\
\hline Reduced Fe, electrolytic & & $\mathrm{Fe}$ & 970 & 50 \\
\hline $\begin{array}{l}\text { Reduced } \mathrm{Fe} \text {, carbonyl } \\
\text { process }\end{array}$ & & $\mathrm{Fe}$ & 980 & 67 \\
\hline
\end{tabular}

* Fe-deficient rats are cured of Fe deficiency by feeding them either a test Fe sample or a reference dose of ferrous sulphate. The cure is measured by haemoglobin or packed cell volume repletion in the rats' blood and bioavailability of samples are reported against a value of 100 for ferrous sulphate. Thus, any Fe sample which is less available than ferrous sulphate will have an RBV of less than 100 and one which is more available than ferrous sulphate will have an RBV greater than 100.

$\dagger$ Ferric orthophosphate contains from one to four molecules of hydration.

$\ddagger$ The precise structures of the Fe salts are uncertain.

a term used to describe turbidity caused by a complex interaction between Fe, copper, tin and $\mathrm{Ca}$ with tannins and protein in beer. The bioavailability and reactivity of $\mathrm{Fe}$ sources may also change during processing and storage, as a result of changes in the chemistry of the Fe. These aspects of the technology of Fe fortification are further expanded by Richardson (1983).

At this stage in the discussion it may seem inconceivable to a food technologist that a nutritionist would wish to add trace elements to any food or drink products, because the majority of his time is likely to be spent trying to remove metal ions and prevent undesirable effects which cause product rejection. However, the food technologist can control and minimize adverse effects of metals in foods by using sequestrants which can hold the metal ion in solution in a non-ionizable, less reactive metal complex.

In attempting to fortify foods with $\mathrm{Fe}$ and other minerals including $\mathrm{Ca}$, it soon becomes evident that potential problems with colour, flavour, texture and quality control may be encountered. For any added nutrient, these problems may increase as a higher proportion of the RDA is included per serving, or as the serving size decreases. Close attention, therefore, must be paid to the effects of the addition of nutrients to foods in terms of their sensory attributes and shelf-life stability. 


\section{COMMUNICATING NUTRITION}

Results of consumer surveys in the UK (Jones Rhodes Associates, 1988) show that, although the majority of interest in nutrition stems from a perceived fear and apprehension about the food supply posing a danger to health in terms of too much fat, sugar, cholesterol and salt, there is still a considerable interest in the addition of nutrients to foods. In the US, examination of consumer responses on their willingness to pay more for nutrients suggested that addition was regarded more favourably in those products which were already perceived to be nutritious, such as milk products and breakfast cereals, but not in snack foods or soft drinks. These consumer perceptions are now reflected by fortification guidelines published by the Food and Drug Administration which discourage the indiscriminate addition of nutrients to foods (United States Food and Drug Administration, 1987b).

Although there is no doubt that the addition of nutrients can be a significant factor in establishing a market for a particular food product, there is, however, little published information in the UK which tells us whether the public understands what nutrient fortification means or whether consumers would be willing to pay more for a product with added nutrients.

Consumers whose interest in nutrition has been awakened will want to be able to assess the nutritional value of the foods they consume, and they will look increasingly to the food label to supply this information. The food-manufacturing industries have responded by a marked revival of interest in the composition of foods, in improved methods of analysis, as well as in the establishment of nutrition databases for information about their products (Richardson, 1987).

\section{CONCLUSION}

Use of ready-prepared foods continues to increase in this country; during preparation some nutrients may be removed or destroyed and others may be added. Food processing may result in changes in the bioavailability of some nutrients. In brief, the manufacturer must not only know the technology of combining ingredients to produce attractive, safe and nutritious foods, but in the current regulatory climate give serious attention to the formulation, labelling and cost implications of existing and proposed food regulations. Product developments, such as the fortification of foods, require the provision of sound advice on technical and legislative aspects from concept research right through to product launch (Freckleton et al. 1989). If the addition of nutrients is desired or intended, questions that will need to be researched include: Do the ingredients support the claims? What labelling requirements may be triggered? How much processing and storage information is necessary to support on-the-shelf nutrition claims? What extra quality control will the new product need to support claims? Will the product contribute substantially to the diet? Is the product designed to be a replacement or alternative to a natural food, and should it be nutritionally equivalent to the natural food it would eliminate?

Changing lifestyles and decreased energy intake of the population during recent years have placed greater emphasis on the need to measure the amounts and the bioavailability of nutrients in the food supply and to promote research which defines forms of nutrients which can be absorbed and utilized by the body. Without this information, assessments of the degree of risk from nutrient excesses or deficiencies cannot be made. All these 
issues are particularly relevant to the addition of nutrients to foods, whether it is as a public health measure or as a selling point in product development.

\section{REFERENCES}

Bauernfeind, J. C. \& Brooke, C. L. (1973). Guidelines for nutrifying 41 processed foods. Food Engineering 45 (6), 91-97.

Bender, A. E. (1978). Food Processing and Nutrition. London: Academic Press.

Benton, D. \& Roberts, G. (1988). Effect of vitamin and mineral supplementation on intelligence of a sample of schoolchildren. Lancet i, 140-143.

Bread and Flour Regulations (1984). Statutory Instrument no. 1304. London: H.M. Stationery Office.

British Nutrition Foundation (1987). Food Processing-a Nutritional Perspective. Briefing Paper no. 11. London: British Nutrition Foundation.

Codex Alimentarius Commission (1985). Report of the 14th Session of the Codex Committee on Foods for Special Dietary Use. Rome: Joint FAO/WHO Food Standard Programme.

Codex Alimentarius Commission (1987). General Principles for the Addition of Essential Nutrients to Foods, Alinorm 87/26, Appendix 5. Rome: FAO.

Counsell, J. N. (1988). Vitamin fortification of foods. In Food Technology International Europe, pp. 211-218 [A. Turner, editor]. London: Sterling Publications Ltd.

Department of Health and Social Security (1980). Foods which Simulate Meat. Report on Health and Social Subjects no. 17. Report of the Panel on novel foods, Committee on Medical Aspects of Food Policy, pp. 1-20. London: H.M. Stationery Office.

Department of Health and Social Security (1981). Nutritional Aspects of Bread and Flour. Report on Health and Social Subjects no. 23. Report by the Committee on Medical Aspects of Fcod Policy, pp. 1-64. London: H.M. Stationery Office.

du Bois, I. (1987). Food enrichment: legislation in Europe. Bibliotheca Nutrito et Dieta 40, 69-81.

European Council Directive (1987). Approximation of the laws of the Member States relating to foodstuffs intended for particular nutritional uses. Official Journal of the European Communities COM (87) 241.

Federation of American Societies for Experimental Biology (1980). Evaluation of the Health Aspects of Iron and Iron Salts as Food Ingredients, pp. 1-71. Bethesda, Maryland: Life Sciences Research Office.

Food Labelling Regulations (1984). Statutory Instrument 1984, no. 1305, as amended. London: H.M. Stationery Office.

Frazer, J. G. (1935). The Golden Bough: the Magic Art and the Evolution of Kings. New York: Macmillan.

Freckleton, A. M., Gurr, M. I., Richardson, D. P., Rolls, B. A. \& Walker, A. F. (1989). Public perception and understanding. In The Human Food Chain, pp. 17-57 [C. R. W. Spedding, editor]. London: Elsevier Applied Science Publishers.

Harris, R. S. \& Karmas, E. (1977). Nutritional Evaluation of Food Processing, 2nd ed. Westport, Connecticut: Avi Publishing Co. Inc.

Jones Rhodes Associates (1988). The National Health Survey. West Bridgeford, Nottinghamshire: Jones Rhodes Associates.

Killeit, U. (1988). The Stability of Vitamins. A Selection of Current Literature. Grenzach-Wyhlen, West Germany: Hoffman-La-Roche AG.

Margarine Regulations (1967). Statutory Instrument no. 1867 as amended. London: H.M. Stationery Office.

Ministry of Agriculture, Fisheries and Food (1974). Food Standards Committee Report on Novel Protein Foods, FSC/REP/62, pp. 1-82. London: H.M. Stationery Office.

National Academy of Sciences (1975). Technology of Fortification of Foods, Proceedings of a Workshop. Washington, DC: National Academy of Sciences.

Richardson, D. P. (1981). Nutrition labelling with special reference to the USA. Proceedings of the Institute of Food Science and Technology 14, 87-102.

Richardson, D. P. (1982). Consumer acceptability of novel protein products. In Developments in Food Proteins-1, pp. 217-246 [B. J. F. Hudson, editor]. Applied Science Publishers Ltd.

Richardson, D. P. (1983). Iron fortification of foods and drinks. Chemistry and Industry 13, 498-501.

Richardson, D. P. (1987). Effects of nutritional guidelines on food marketing and new product development. In Food Acceptance and Nutrition, pp. 433-442 [J. Solms, D. A. Booth, R. M. Pangborn and O. Raunhardt, editors]. London: Academic Press. 
Taitz, L. S. (1988). Which children need vitamins? British Medical Journal 296, 1753.

United States Food and Drug Administration (1987a). Code of Federal Regulations. Title 21, Nutrition Labelling of Food, Part 101.9, Sodium Labelling, Part 101.13. Washington, DC: Food and Drug Administration.

United States Food and Drug Administration (1987b). Code of Federal Regulations. Title 21, Nutritional Quality Guidelines for Foods, Part 104.5. Washington, DC: Food and Drug Administration.

Vitamin Information Service (1988). Press Releases. London: Vitamin Information Service. 